\title{
Real-World Breast Cancer Patient Follow-Up Practices by Medical Oncologists in India-A Survey Report
}

\author{
Amol Patel ${ }^{1}$ Vineet Govinda Gupta ${ }^{2}$ Bhupesh Guleria \\ Kaushik Mahadevapura Ramegowda ${ }^{6}$ \\ ${ }^{1}$ Department of Medicine, Oncology Centre, Indian Naval Hospital \\ Ship, Asvini, Colaba, Mumbai, Maharashtra, India \\ 2 Department of Medical Oncology, Artemis Hospitals, Gurgaon, \\ Haryana, India \\ ${ }^{3}$ Malignant Diseases Treatment Centre, Command Hospital (SC), \\ Pune, Maharashtra, India \\ ${ }^{4}$ Department of Medical Oncology, Post Graduate Institute of Medical \\ Education \& Research, Chandigarh, India
}

South Asian J Cancer 2022;11(1):9-13.
Address for correspondence Amol Patel, MD, DM, Department of Medicine, Oncology Centre, Indian Naval Hospital Ship, Asvini, Colaba, Mumbai, Maharashtra, 400005, India (e-mail: dr.amolpatel@hotmail.com).

${ }^{5}$ Department of Medical Oncology, Asian Institute of Medical Sciences, Faridabad, Haryana, India

${ }^{6}$ Department of Medical Oncology, Malignant Diseases Treatment Centre, Army Hospital Research \& Referral, New Delhi, India

\section{Abstract

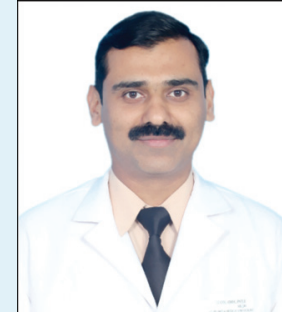 \\ Amol Patel \\ Keywords \\ - Breast cancer \\ - Follow-up practices \\ - India \\ - Mammography \\ - Survey}

Background In India, breast cancer patients' post-treatment follow-up practices are not known. We did this survey to understand how the breast cancer patients are followed-up and tried to explore the challenges associated with it.

Methods We conducted a survey-based study among Indian oncologists. Seven questions were framed pertaining to follow-up practices. Answers were provided in the form of multiple options. Google forms platform was used. Survey was circulated through social media apps and through mail. We sought suggestions and opinions to address the challenges from participants.

Results A total of 158 medical oncologists responded to this survey. 10\% were not aware that only history and clinical examination are the scientific recommendations for follow-up. Ninety percent of the medical oncologists felt clinical breast examination as an uncomfortable practice for patients and physicians and $39 \%$ ordered a chest X-ray and an ultrasound abdomen. Annual mammogram was ordered by $83 \%$, and blood investigations were recommended by $14 \%$ routinely. The majority $(49.6 \%)$ felt that the absence of a female attendant, physician and patient factors were responsible for nonadherence to clinical breast examination. The DEXA scan was recommended by 84 (53\%) medical oncologists regularly for patients on aromatase inhibitors, while 23 (14\%) did not recommend it.

Conclusion There is a disparity between scientific recommendations and real-world follow-up practices. A large number of medical oncologists relied on chest X-ray and ultrasound abdomen. There is an unmet need to address this issue.

\section{Introduction}

Breast cancer is the most common cancer in India. In 2018, 162468 new cases of breast cancer were diagnosed, and the

DOI https://doi.org/10.1055/s-0041-1739187 ISSN 2278-330X

How to cite this article: Patel A, Gupta VG, Guleria B, et al. Real-World Breast Cancer Patient Follow-Up Practices by Medical Oncologists in India-A Survey Report South Asian J Cancer 2022;11(1):9-13. outcomes of these patients are improving. ${ }^{1}$ Careful follow-up after end of therapy is important for timely detection of recurrences or complications of therapy. Summary of
(C) 2022. MedIntel Services Pvt Ltd. All rights reserved.

This is an open access article published by Thieme under the terms of the Creative Commons Attribution-NonDerivative-NonCommercial-License, permitting copying and reproduction so long as the original work is given appropriate credit. Contents may not be used for commercial purposes, or adapted, remixed, transformed or built upon. (https://creativecommons.org/licenses/by-nc-nd/ 4.0/)

Thieme Medical and Scientific Publishers Pvt. Ltd., A-12, 2nd Floor, Sector 2, Noida-201301 UP, India 
Table 1 Summary of scientific recommendations for follow up of asymptomatic breast cancer patients post chemotherapy

\begin{tabular}{|c|c|c|c|}
\hline & $\operatorname{NCCN}(2)$ & ESMO (3) & ASCO (4) \\
\hline History and physical examination & $\begin{array}{l}1-4 \text { times per year for } 5 \text { years } \\
\text { (every } 4 \text { to } 6 \text { months) then yearly }\end{array}$ & $\begin{array}{l}\text { Every } 3 \text { to } 4 \text { months for } 2 \text { years, } \\
6-8 \text { monthly for } \\
3-5 \text { years, annually } \\
\text { thereafter. Interval of visits } \\
\text { should be adapted to risk of re- } \\
\text { lapse and patient's needs. }\end{array}$ & $\begin{array}{l}\text { Every } 3 \text { to } 6 \text { months for first } \\
3 \text { years, } 6-12 \text { months for next } \\
2 \text { years, annually thereafter }\end{array}$ \\
\hline Annual mammography & $\begin{array}{l}\text { Recommended. Routine imaging } \\
\text { of reconstructed breast is not } \\
\text { recommended }\end{array}$ & $\begin{array}{l}\text { Recommended. Ultrasound and } \\
\text { MRI breasts can be considered if } \\
\text { needed }\end{array}$ & $\begin{array}{l}\text { Recommended. Post BCS after } \\
1 \text { year of initial } \\
\text { mammogram and at least } \\
6 \text { months after radiation therapy }\end{array}$ \\
\hline CXR and US-A & Not recommended & Not recommended & Not recommended \\
\hline CBC, LFT, RFT & Not recommended & Not recommended & Not recommended \\
\hline PET-CT & Not recommended & Not recommended & Not recommended \\
\hline CA15-3 & Not recommended & Not recommended & Not recommended \\
\hline Bone mineral density monitoring & $\begin{array}{l}\text { Recommended. At baseline and } \\
\text { thereafter (On Al or chemother- } \\
\text { apy induced amenorrhea) }\end{array}$ & Recommended & Recommended \\
\hline $\begin{array}{l}\text { Endometrial thickness monitor- } \\
\text { ing for patients } \\
\text { receiving Tamoxifen }\end{array}$ & $\begin{array}{l}\text { Yes, gynecologic assessment every } \\
12 \text { months if uterus present }\end{array}$ & $\begin{array}{l}\text { If symptoms suggestive } \\
\text { of this complication, } \\
\text { appropriate investigations should } \\
\text { be advised }\end{array}$ & $\begin{array}{l}\text { Regular gynecologic follow up is } \\
\text { recommended }\end{array}$ \\
\hline $\begin{array}{l}\text { Assessment of physical and psy- } \\
\text { chosocial and late effects of } \\
\text { treatment }\end{array}$ & Recommended & Recommended & Recommended \\
\hline Genetic counseling and screening & $\begin{array}{l}\text { Recommended. Periodic screen- } \\
\text { ing and referral to genetic } \\
\text { counseling as indicated }\end{array}$ & $\begin{array}{l}\text { Recommended for high risk indi- } \\
\text { viduals a }\end{array}$ & $\begin{array}{l}\text { Recommended as per US Pre- } \\
\text { ventive Services Task Force }\end{array}$ \\
\hline
\end{tabular}

Abbreviations: ASCO, American Society of Clinical Oncology; CBC, complete blood count; CXR, chest X-ray; ESMO, European Society of Medical Oncology; LFT, liver function test; NCCN, National Comprehensive Cancer Network; PET-CT, positron emission tomography-computed tomography; RFT, renal function tests; US-A, ultrasound abdomen.

${ }^{a}$ strong family history of breast, ovarian, pancreatic and/or high-grade/metastatic prostate cancer; diagnosis of breast cancer before the age of 50 years, diagnosis of triple negative breast cancer before the age of 60 years, personal history of ovarian cancer or second breast cancer or male sex.

recommendations regarding the same by various scientific bodies are depicted in - Table 1 . The follow-up recommendations of breast cancer patients after completion of treatment are dependent on good history taking and clinical breast examination (CBE), every 3 to 4 months for initial 2 years and then every 6 months from third to fifth year and annually thereafter. ${ }^{2}$ Annual mammography is recommended for all breast cancer patients. ${ }^{2-4}$ Bone health monitoring by dual-energy X-ray absorptiometry (DEXA) scan is recommended, and investigations like chest X-ray (CXR), computed tomography (CT) scan of chest and abdomen, ultrasound of abdomen (US-A) or positron emission tomography (PET)-CT scan are not recommended unless there are clinical symptoms and/or signs. The current evidence for follow-up and screening practices is not considered as strong evidence for recommendations. ${ }^{5}$ The randomized studies conducted in the 80s and 90s addressing the role of intensive investigations in breast cancer follow-up failed to demonstrate an overall survival benefit. ${ }^{6-8}$ Advances in metastatic breast cancer treatment have occurred after the conduct of these studies. The survival outcomes in metastatic breast cancer have increased phenomenally over 1990 to 2009. ${ }^{9}$ Detecting relapse early by investigations like CXR and US-A might lead to improved survival and/or quality of life. Many physicians and institutional practices routinely advocate for
CXR, US-A, and CA15-3 as a part of follow-up. ${ }^{10-12}$ There is a wide disparity between recommendations and adherence to them.

The literature has a lacuna on real-world practices and challenges associated with it in India. We conducted this survey-based study to understand how breast cancer patients are followed-up. We addressed the challenges related to nonadherence to scientific recommendations.

\section{Methods}

We conducted a survey-based study among Indian medical oncologists who are treating breast cancer patients. Survey form was made pertaining for follow-up practices after completion of treatment of breast cancer patients in curative setting ( - Table 2). Questions on history and physical examination, $\mathrm{CBE}$, issues related to $\mathrm{CBE}$, annual mammography, CXR and US-A, complete blood count (CBC), liver function tests (LFTs), renal function tests (RFTs), and bone health monitoring by DEXA scan were included. Questions were framed to understand the challenges in following-up of patients. Answers were provided in the form of multiple options. This survey was conducted from January 3 till July 31,2020 . The survey was circulated through social media apps and through mails. Google forms platform was used. As 
Table 2 Survey form

\begin{tabular}{|c|c|}
\hline Question 1. & Do you recommend yearly mammography for all patients? \\
\hline Answer 1. & - Yes/no \\
\hline Question 2. & Do you feel breast examination by clinician is not universally practiced? \\
\hline Answer 2. & - Yes/no \\
\hline Question 3. & What factors make breast examination is an uncomfortable practice? \\
\hline \multirow[t]{5}{*}{ Answer 3.} & 1. Patient factor (conservativeness and unwillingness) \\
\hline & 2. Clinician factor (fear of litigation) \\
\hline & 3. Absence of female attendant in OPD/clinics \\
\hline & 4. all of the above \\
\hline & 5. other reasons \\
\hline Question 4. & Do you advise CXR and US-A for screening in asymptomatic breast cancer patient? \\
\hline Answer 4. & Yes/No \\
\hline Question 5. & $\begin{array}{l}\text { Do you know that only history and clinical examination is recommended in routine follow up } \\
\text { of breast cancer patients? }\end{array}$ \\
\hline Answer 5. & Yes/No \\
\hline Question 6. & How often you recommend CBC, LFT and RFT in routine follow-up of these patients? \\
\hline \multirow[t]{4}{*}{ Answer 6.} & 1. Occasionally \\
\hline & 2. Symptom directed \\
\hline & 3. Always \\
\hline & 4. other - \\
\hline Question 7. & Do you recommend DEXA scan? \\
\hline Answer 7. & Yes/No \\
\hline
\end{tabular}

Abbreviations: CBC, complete blood count; CXR, chest X-ray; DEXA, dual-energy X-ray absorptiometry; LFT, liver function test; RFT, renal function test; US-A. ultrasound abdomen.

survey was circulated through social media apps, responses from only medical oncologists were taken for analysis.

\section{Results}

A total of 158 medical oncologists participated out of 344. Majority (90\%) of medical oncologists were aware of the universal recommendation of history and physical examination in follow-up of breast cancer patients postchemotherapy.

CBC, LFTs, and RFTs were ordered by $14 \%$ during every visit and $68 \%$ ordered these investigations only as per symptoms (-Fig. 1).

A total of 155 medical oncologists responded on factors relating to $\mathrm{CBE}$ as an uncomfortable practice (-Fig. 2). $83 \%$ $(n=130)$ ordered the annual mammography for their patients (-Fig. 3). Only 7\% felt that the CBE can be easily practiced in their workplace without any limitations.

Absence of female attendants in the clinic was the only factor of concern for $12.2 \%(n=19)$ of medical oncologists. Physician's reluctance, fear of litigation by female patient, and time constraints were the factors reported by $2 \%, 2 \%$, and $1 \%$, respectively. Patient factor of conservativeness and unwillingness was mentioned by 32 (20\%) of the medical oncologists. Majority (49.6\%) felt that the absence of a female attendant, physician and patient factors are all responsible for less practice of CBE.
CXR and US-A were advised by $39 \%$ of medical oncologists ( - Fig. 4).

The DEXA scan was recommended by 84 (53\%) medical oncologists regularly for patients on aromatase inhibitors, while 23 (14\%) did not recommend the DEXA scan. Only three asked for DEXA scan as per symptoms. Others did not answer this question.

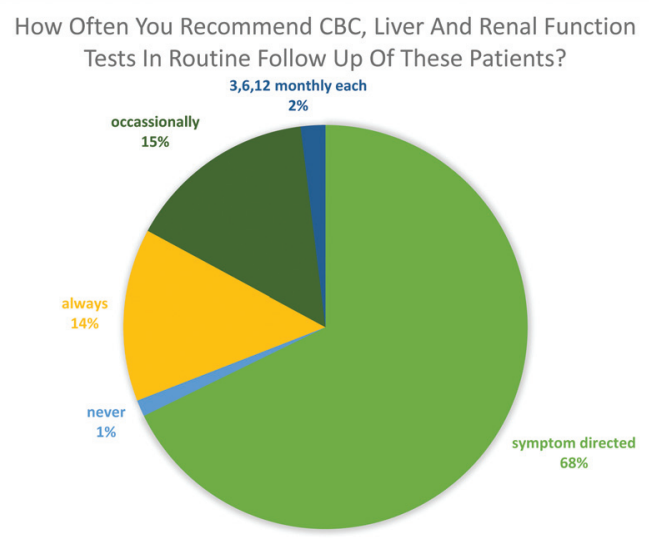

Fig. 1 Various patterns of blood investigations. CBC, complete blood count. 


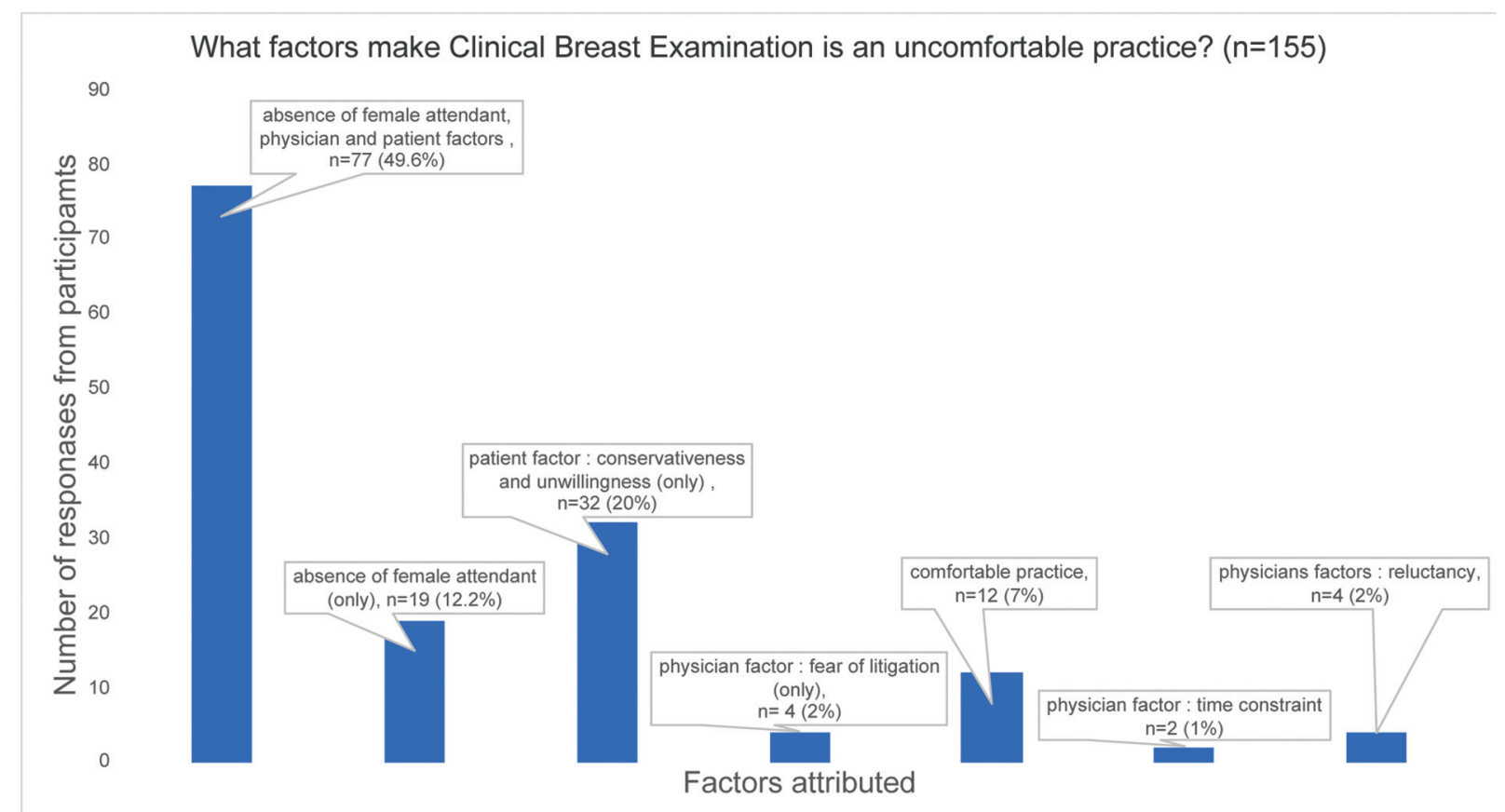

Fig. 2 Factors making clinical breast examination an uncomfortable practice (five other responses-logistics, female doctor preference, lack of awareness).

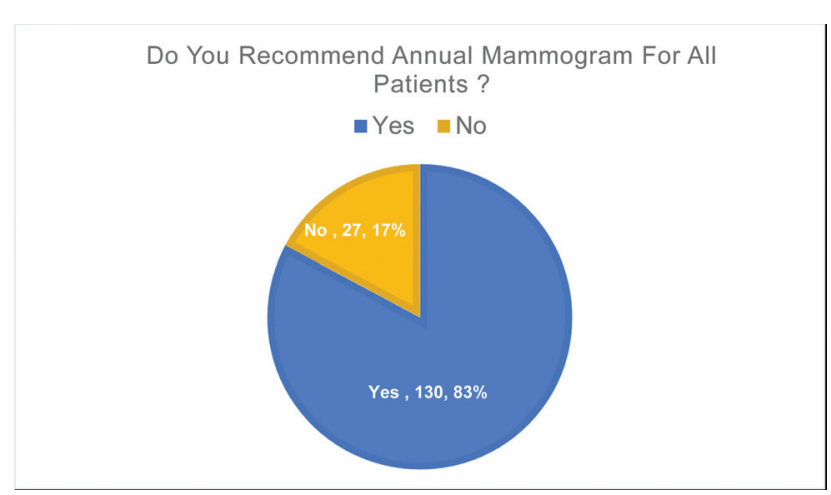

Fig. 3 Percentage of annual mammogram recommendation by Indian medical oncologists $(n=157)$.

Do you advise Chest $\mathrm{X}$-ray and Ultrasound abdomen for screening in asymptomatic breast cancer patient?

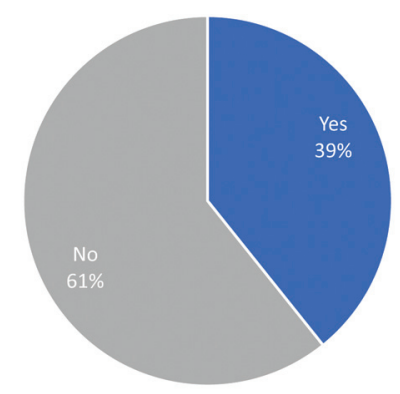

Fig. 4 Use of chest X-ray (CXR) and ultrasound abdomen (US-A) asymptomatic breast cancer follow-up.

\section{Discussion}

In a systematic literature review by de Guzman et al, the median adherence to follow-up recommendations of breast cancer patients in eight European countries was $74 \%$ (range $0-84 \%) .{ }^{10}$ Similarly, in the survey conducted by Foster et al on guideline adherence in American medical oncologists, 82\% ordered annual mammogram, and $22 \%$ asked for CA15-3 and chest imaging every 6 months for 5 years by $16 \%{ }^{11}$ In our survey, $83 \%$ ordered the annual mammogram, and CXR and US-A were ordered by $39 \%$ of medical oncologists, which is very high in comparison to American medical oncologists.

In India, sociocultural issues introduce limitations in conducting CBE. Only $7 \%(n=12)$ felt CBE as a comfortable practice. This fact was not reported before. The predominant patient factors were conservativeness and unwillingness addressed by $20 \%$ of medical oncologists; however, this finding is limited by absence of patient's view on this. Future studies should address this issue. The medical history taking and clinical examination is considered by many to be a declining art. ${ }^{13}$ The backbone of a follow-up is clinical examination; an inadequate clinical examination may miss important findings, leading to delay in recognition of relapse. In many parts of the world, the ability to perform a proper CBE might be limited by sociocultural factors and economics (e.g., availability of adequate staff, examination rooms with privacy).

Physician factors can be overcome by increasing awareness for benefits of these essential parts of patient care, which are taught during residency. ${ }^{14}$ One of the reasons emphasized for nonadherence to CBE was absence of a female attendant (12\%). Such barriers can be overcome by providing the female attendants during breast cancer clinic hours, although it may not be possible in every clinic. 
Ten percent of medical oncologists were not aware or did not follow the existing guidelines of follow-up of breast cancer patients, which is not reported before. The practice of DEXA scan recommendation also deviated from the scientific recommendations. ${ }^{15}$ Only $53 \%$ percent have advised for regular bone health monitoring.

Although the existing guidelines are based on older studies, cost is saved if guidelines are adhered, and unnecessary investigations will not be prescribed. ${ }^{11}$ These investigations might also lead to unnecessary invasive procedures and fear of uncertainty and increase stress for the patients. However, there is a missing link of newer studies between recommendations based on older studies and real-world practices and their challenges.

Phenomenal progress has been made in treatment of breast cancer in the last four decades, and this was achieved because of understanding of the disease and treatment of breast cancer as three subsets (hormone positive, Her2neu positive and triple negative). ${ }^{16}$ The guidelines of follow-up are based on old data and not on robust scientific data. ${ }^{5,10}$ There is a need to readdress this issue of follow-up of breast cancer patients, as they are not universally practiced, and newer therapies are available for three subtypes of breast cancer. It will be prudent to start follow-up study, according to subtypes prospectively, as new treatments might lead to change in outcomes of these patients. Indian oncology societies should come forward and formulate India specific guidelines.

\section{Strength of the Study}

For the first time, such a survey was conducted that brought out the issues inherent to follow-up practices of breast cancer patients after completion of chemotherapy. As the data on follow-up practice is very old, this survey brings out the importance in this important field of oncology practice, which has wide implications. Such topics are never discussed in pharma-driven medical oncology conferences.

\section{Limitations of the Study}

The denominator of respondents might be different, as survey was circulated through multiple social media apps. However, number of respondents was large. Only medical oncologists were surveyed. Surgical and radiation oncologists were not included in this study. Survey lacked the questions of demographics of respondents like age, sex, and region of practice. Pre- and postmenopausal patients' category was not considered for use of DEXA scan. The practice domain of medical oncologists is not taken into consideration like academic versus nonacademic or private versus government hospitals.

\section{Conclusion}

This survey-based study highlighted the challenges for follow-up of breast cancer patients in India. Scientific recommendations are not universally followed. CXR and US-A are recommended by $39 \%$ of the medical oncologists, and $90 \%$ felt $\mathrm{CBE}$ as an uncomfortable practice for patients and physicians. Annual mammogram is ordered by $83 \%$ and blood investigations were recommended by $14 \%$ routinely.

\section{Conflict of Interest}

The authors declare no conflicts of interest.

\section{Acknowledgment}

We kindly acknowledge Prof. Benjamin O. Anderson, MD, FACS for his expert guidance on this manuscript.

\section{References}

1 Doval DC, Radhakrishna S, Tripathi R, et al. A multi-institutional real world data study from India of 3453 non-metastatic breast cancer patients undergoing upfront surgery. Sci Rep 2020;10(01):5886

2 Lurie RH, Anderson BO, Abraham J, et al. NCCN Guidelines Version 6.2020. Breast Cancer 2020

3 Cardoso F, Kyriakides S, Ohno S, et al; ESMO Guidelines Committee. Electronic address: clinicalguidelines@esmo.org. Early breast cancer: ESMO Clinical Practice Guidelines for diagnosis, treatment and follow-up†. Ann Oncol 2019;30(08):1194-1220

4 Khatcheressian JL, Hurley P, Bantug E, et al; American Society of Clinical Oncology. Breast cancer follow-up and management after primary treatment: American Society of Clinical Oncology clinical practice guideline update. J Clin Oncol 2013;31(07):961-965

5 Henry NL, Hayes DF, Ramsey SD, Hortobagyi GN, Barlow WE, Gralow JR. Promoting quality and evidence-based care in earlystage breast cancer follow-up. J Natl Cancer Inst 2014;106(04): dju034-dju034

6 Rosselli Del Turco M, Palli D, Cariddi A, Ciatto S, Pacini P, Distante V. Intensive diagnostic follow-up after treatment of primary breast cancer. A randomized trial. National Research Council Project on Breast Cancer follow-up. JAMA 1994;271(20):1593-1597

7 Palli D, Russo A, Saieva C, et al; National Research Council Project on Breast Cancer Follow-up. Intensive vs clinical follow-up after treatment of primary breast cancer: 10-year update of a randomized trial. JAMA 1999;281(17):1586

8 Ghezzi P, Magnanini S, Rinaldini M, et al; The GIVIO Investigators. Impact of follow-up testing on survival and health-related quality of life in breast cancer patients. A multicenter randomized controlled trial. JAMA 1994;271(20):1587-1592

9 Welt A, Bogner S, Arendt M, et al. Improved survival in metastatic breast cancer: results from a 20-year study involving 1033 women treated at a single comprehensive cancer center. J Cancer Res Clin Oncol 2020;146(06):1559-1566

10 Niño de Guzmán E, Song Y, Alonso-Coello P, et al. Healthcare providers' adherence to breast cancer guidelines in Europe: a systematic literature review. Breast Cancer Res Treat 2020;181 (03):499-518

11 Foster JA, Abdolrasulnia M, Doroodchi H, McClure J, Casebeer L. Practice patterns and guideline adherence of medical oncologists in managing patients with early breast cancer. J Natl Compr Canc Netw 2009;7(07):697-706

12 Zaluska-Kusz J, Litwiniuk M. 194P follow up after breast cancer in real life. Ann Oncol 2020;31:S86

13 Feddock CA. The lost art of clinical skills. American Journal of Medicine 2007;120:374-8

14 Bryan T, Snyder E. The clinical breast exam: a skill that should not be abandoned. J Gen Intern Med 2013;28(05):719-722

15 Shapiro CL, Van Poznak C, Lacchetti C, et al. Management of osteoporosis in survivors of adult cancers with nonmetastatic disease: ASCO clinical practice guideline. J Clin Oncol 2019;37 (31):2916-2946

16 Hayes DF. Further progress for patients with breast cancer. N Engl J Med 2019;380(07):676-677 